\title{
Regras Constitutivas Podem Criar uma PRÁTICA?*
}

\author{
Giuseppe Lorini* *
}

1 Regras constitutivas e sentido de jogo. 2 Xadrez como Jogo vs. Xadrez como rito. 3 Atividade constituída por regras vs. Prática. 4 A investigação impossível de Averróis. Referências

\begin{abstract}
RESUMO
O autor investiga o papel das regras constitutivas na construção da realidade social. Ele nega que as regras constitutivas sejam condição suficiente de uma prática como um jogo de xadrez. Para criar uma nova prática com regras, é necessário que já exista uma gramática dessa prática, ou seja, o sentido dessa prática (por exemplo, o sentido de jogo). É a gramática de uma prática - e não suas regras constitutivas - que determina a natureza de uma prática. O sentido de uma prática não pode ser criado por regras constitutivas.
\end{abstract}

Palavras-chave: Regras constitutivas. Prática. Ontologia social. Fato institucional.

\section{REGRAS CONSTITUTIVAS E SENTIDO DE JOGO}

Este ensaio se refere à ontologia social. Em ontologia social, uma distinção fundamental é aquela (proposta pelo filósofo americano John R. Searle) entre fatos brutos e fatos institucionais.

* Tradução para a língua portuguesa gentilmente realizada por Angélica Mota Cabral. O artigo foi publicado em língua inglesa originalmente no periódico Praxis Filosófica e está disponível em http://praxis.univalle.edu.co/index.php/filosofica/article/view/1930/2971. (Esta nota foi alterada a pedido do autor.)

** Giuseppe Lorini ensina Filosofia do Direito e Teoria Geral do Direito na Universidade de Cagliari (Itália) desde 2005. Ensinou também na Universidade de Camerino (Itália) e na Universidade de Pavia (Itália). Ele fez seu doutorado em "Filosofia Analítica e Teoria Geral do Direito" em 1997 na Universidade Estadual de Milão (Itália) com uma tese intitulada Dimensões da Instituição (Dimensioni dell'istituzionale). Foi professor visitante na Universidade Internacional de Andalucía (Espanha), Universidade de Oviedo (Espanha), Uniwersitet Gdański (Polónia), Universidade de Nagoya (Japão). Foi professor visitante na Universidade da Califórnia em Berkeley (EUA) e na Universidad de Sevilla (Espanha). É membro do conselho editorial da revista filosófica "Argumenta". Journal of Analytic Philosophy" e membro do Conselho Consultivo Internacional da revista polaca "Ruch Prawniczy, Ekonomiczny i Socjologiczny "("O Jornal Jurídico, Econômico e Sociológico "). Principais interesses: filosofia de normatividade, ontologia social, filosofia de lógica deôntica, antropologia jurídica e etologia legal. E-mail: lorini@unica.it (Esta nota foi alterada a pedido do autor.) 
Para Searle ${ }^{1}$, os fatos institucionais são fatos que, ao contrário dos fatos brutos, pressupõem a existência de certas "instituições" humanas. $\mathrm{O}$ adjetivo 'institucional', que Searle utiliza para qualificar tipos de fato deriva dessa definição de fatos institucionais.

Se alguém ignora essa distinção, pode cometer o erro de confundir status institucional (como ser um Presidente da Câmara, um Juiz e um Bispo) e objetos que são apenas indicadores de status. Swift ${ }^{2}$ descreve essa confusão de forma genial, da seguinte maneira:

Estes animais, que são vulgarmente chamados ternos, ou vestimentas, feitos de acordo com certas composições recebem diferentes denominações. Se um deles for decorado com uma corrente de outro, e uma beca vermelha, e um bastão branco, e um grande cavalo, é chamado um Presidente da Câmara; se certos arminhos e peles são colocados em certa posição, nós o chamamos de Juiz, e, então, uma adequada conjunção de linho e seda preta é intitulada de Bispo.

De modo a caracterizar o conceito de fato institucional e distinguir fatos institucionais e fatos brutos, Searle utiliza o conceito de uma "regra constitutiva". De fato, para Searle ${ }^{3}$, "instituições" são sistemas de regras constitutivas.

Searle distingue dois diferentes tipos de regras: regras regulativas e regras constitutivas. Para Searle 4 , "regras regulativas regulam uma atividade preexistente, uma atividade cuja existência é logicamente independente das regras", enquanto "regras constitutivas constituem [...] uma atividade cuja existência é logicamente dependente das regras". Por exemplo, "as regras do futebol ou do xadrez [...] não meramente regulam o jogo de futebol ou de xadrez, mas elas criam mesmo a possibilidade de jogar tais jogos."

Nesse contexto, meu ponto de partida é a tese de que as regras constitutivas criam a possibilidade de novas formas de comportamento. A questão que proponho, no presente ensaio, é: é realmente verdade que uma nova (espécie de) atividade institucional pode ser criada unicamente por regras constitutivas? Este ensaio investiga a forma por meio da qual uma atividade institucional é criada por meio de regras constitutivas, mas também os limites e as condições da criação de atividades institucionais pelas regras constitutivas. Em outras palavras, a questão é: as regras constitutivas de uma prática constituem uma condição necessária e suficiente do tipo de prática a qual é seu objeto?5

Minha resposta é esta: as regras constitutivas podem criar a possibilidade de novas formas de comportamento (uma nova atividade constituída por regras), mas não podem, por si mesmas, criar uma nova prática. Elas não podem ser uma condição necessária e suficiente de uma prática.

De maneira a explicar e demonstrar essa tese, inicio averiguando a tese defendida por Searle ${ }^{6}$ :

A atividade de jogar xadrez é constituída pelo agir em concordância com regras apropriadas. 
Contudo, é verdade que a atividade de jogar xadrez consiste em agir de acordo com as regras constitutivas do xadrez? Em outras palavras, a atividade de jogar xadrez consiste em agir de acordo com as regras constitutivas que constituem os movimentos possíveis e os valores das peças de xadrez?

Entendo como 'regras constitutivas do xadrez' aquelas que são específicas do jogo de xadrez; em outros termos, todas as regras que definem os movimentos possíveis no jogo e o valor das peças de xadrez. ${ }^{7}$ São aquelas regras que distinguem o jogo de xadrez do futebol ou do jogo de damas.

Outro filósofo, Hubert Schwyzer, criticou a tese de Searle. Schwyzer não nega que o xadrez é um jogo jogado pela ação em conformidade com as regras do jogo. Em outras palavras, Schwyzer não negou que o jogo de xadrez é uma atividade regida por regras. O que ele nega é:

Primeiro, que o sentido de jogo que caracteriza a atividade de jogar xadrez deriva da ação em conformidade com as regras do jogo.

Segundo, que o sentido de jogo que caracteriza a instituição chamada "xadrez" é constituído pelas regras do xadrez.

(i) Primeiro, Schwyzer nega que o sentido de jogo que carateriza a atividade de jogar xadrez consista em agir em conformidade com as regras do xadrez:

Há toda a diferença do mundo entre dizer que o jogo do xadrez é definido por suas regras ou que o xadrez é um jogo executado de acordo com estas regras, e dizer que a atividade de jogar xadrez é constituída pela ação em conformidade com estas regras, ou que as regras definam a atividade. A primeira é irrepreensível, a última é falsa. ${ }^{8}$

Para Schwyzer,9 "Jogar xadrez não consiste em agir de acordo com as regras. As regras não explicam o conceito de jogar xadrez; elas não estabelecem o que é jogar xadrez." Agir de acordo com tais regras não é uma condição suficiente para o fato de que se está jogando xadrez.

Uma observação similar ocorre em Schächter. ${ }^{10}$ Schächter argumenta que não é suficiente agir de acordo com as regras do xadrez para jogar xadrez. No caso de uma pessoa que pratica as regras do xadrez com seu instrutor, essas duas pessoas não estão jogando xadrez. Na terminologia de Schächter, elas não estão "usando" as regras, mas, apenas, demonstrando-as. Escreve Schächter:

No ensino do xadrez, um instrutor pode continuar praticando as regras do jogo com seu aluno, de tal maneira que, na sequência usual (movimento - contramovimento), o aluno mova suas peças de acordo com o prescrito pelas regras. Alguém pode indagar: estes dois estão jogando xadrez ou não?[...] Devemos dizer que eles estão, pois todas as regras estão sendo obedecidas. Porém, em outro sentido, poderíamos dizer que eles não estão, pois estão jogando meramente para demonstrar as regras do jogo, estão exercendo sua gramática. Contanto que isso seja visto meramente como 
uma demonstração de regras, isso não pertence ainda ao jogo; mas, tão logo abandonemos o modo de demonstração, estaremos jogando xadrez. (Para decidir se é o caso de demonstração ou, na verdade, de utilização das regras, não se pode fazer mais do que perguntar aos jogadores ou inferir suas intenções por meio de seu comportamento.)

(ii) Segundo, Schwyzer também nega que o sentido de jogo que caracteriza o jogo de xadrez seja constituído pelas regras de xadrez. Como escreve Schyzer:

Que o xadrez é um jogo e de modo algum uma regra do jogo. ${ }^{11}$

O problema aqui é: em que consiste o sentido de jogo de uma atividade como jogar xadrez?

\section{XADREZ COMO JOGO VS. XADREZ COMO RITO}

Schwyzer explica e prova que a tese aparentemente contra intuitiva de que o sentido de jogo não é intrínseco à atividade constituída pelas regras constitutivas do xadrez, propondo um experimento mental:

Imagine o que se segue. Estou aqui em Ruritânia algum tempo, e posso falar o idioma toleravelmente bem. Um dia, acompanho meu anfitrião e sua família a uma certa construção, onde um grande número de pessoas estavam sentadas em um círculo no chão, murmurando entre si de forma agitada. No centro do círculo está uma pequena mesa com duas cadeiras, e, na mesa, um tabuleiro de xadrez com as peças arranjadas como que para o início de uma partida. Depois de um tempo, dois homens em roupas elaboradas entram na sala e sentam-se em lados opostos da mesa, momento em que aqueles sentados no chão fazem silêncio e passam a assistir atentamente. Os homens na mesa então procedem, com o que parece ser um ar de grande concentração, a mover as peças de xadrez sobre o tabuleiro de acordo com as regras de xadrez. Parece-me, no entanto, que eles jogam um jogo bastante selvagem, e não vejo qualquer estratégia consistente nos movimentos de nenhum dos jogadores. A excitação aumenta até que, depois de cerca de uma hora, as brancas dão xeque-mate nas pretas. Então todos os presentes, inclusive ambos os homens à mesa, mostram sinais de extremo alívio; eles esfregam suas sobrancelhas, sorriem e parabenizam um ao outro. ${ }^{12}$

Continuando com seu experimento mental, Schwyzer imagina que, ao retornar para casa, ele mostra seu próprio tabuleiro de xadrez ao seu anfitrião e o convida para jogar. Porém, aqui está a reação surpreendente de seu anfitrião ao seu pedido: "Ele se torna pálido, está horrorizado e consternado, e insiste que eu guarde o jogo imediatamente. 'Blasfemador!' ele exclama. 'Você quer jogar xadrez comigo? E você forja o tabuleiro e as peças de xadrez?". ${ }^{13}$ 
Por que o anfitrião de Schwyzer reagiu dessa maneira ao simples convite para jogar xadrez? Schwyzer entende a razão de tal reação inesperada quando seu anfitrião lhe explica em que consiste a prática do xadrez em Ruritânia:

Há, ele diz, apenas um tabuleiro de xadrez para cada comunidade. O Xadrez é promulgado uma vez por ano pelo sacerdote da comunidade com o fim de determinar a vontade dos deuses. Se o branco vencer o preto, a comunidade e as colheitas irão florescer; se o preto vencer o branco, haverá problemas. ${ }^{14}$

Então, à pergunta de Schwyzer se o branco deve sempre ganhar, o anfitrião, ainda mais chocado, responde desta forma: "O xadrez não é um duelo ou uma batalha. É um rito sagrado. Não há, absolutamente, vitórias ou derrotas”. ${ }^{15}$

Nesse ponto, o mal-entendido é revelado: em Ruritânia, o xadrez não é um jogo, mas um rito religioso que é realizado apenas uma vez ao ano pelo sacerdote da comunidade ${ }^{16}$. O rito do xadrez não é uma forma de competição: no rito do xadrez, não se pode vencer ou perder, pois vitória e derrota não são partes da gramática do rito.

Consequentemente, para a gramática do rito, no xadrez de Ruritania, não faz sentido falar em estratégia.

Em seu experimento mental, Schwyzer foca no fato de que as diferenças entre o jogo de xadrez e o rito do xadrez não são determinadas pelas regras constitutivas do xadrez. De fato, a atividade das duas práticas (rito do xadrez e jogo de xadrez) é regida pelas mesmas regras: as regras constitutivas do xadrez.

Porém, onde está, então, a diferença entre as duas práticas?

(i) A diferença entre as duas práticas não aparece no nível bruto da descrição da ação. Não é perceptível na observação de meras atividades físicas que compõem as duas práticas.

Adicionalmente, a diferença entre as duas práticas não consiste mesmo em eventos mentais nas mentes dos jogadores. Escreve Schwyzer:

A diferença entre o rito do xadrez e o jogo de xadrez não está de maneira alguma naquilo que acontece sobre o tabuleiro, nem em qualquer coisa nas mentes daqueles que estão realizando os movimentos. ${ }^{17}$

(ii) A diferença entre as duas práticas não aparece nem mesmo no nivel institucional da descrição da ação. De fato, as duas práticas, compartilhando o mesmo sistema de regras, necessariamente também compartilham o mesmo suporte institucional consistente em uma atividade em conformidade com as regras constitutivas do xadrez.

(iii) Em vez disso, a diferença entre as duas práticas consiste na função diferente, no valor diferente que a atividade tem na vida cotidiana daqueles que a praticam: "A diferença está completamente fora do tabuleiro, naquilo que Wittgenstein chama de "papel" da atividade nas vidas daqueles os quais a praticam". ${ }^{18}$ 
Para Schwyzer, é a gramática diferente das duas atividades que distingue o jogo de xadrez do rito do xadrez. É a gramática de uma prática - e não suas regras constitutivas - que determina sua natureza e, consequentemente, seu sentido de rito ou seu sentido de jogo: "A natureza de uma dada prática é definida não por suas regras, mas por sua "gramática". ${ }^{19}$

Schwyzer ${ }^{20}$ acredita que o fato "de que o xadrez é um jogo não é de forma alguma uma regra do jogo.” É uma proposição gramatical ${ }^{21}$. Nessa perspectiva, ele escreve:

O que faz de uma partida de xadrez o tipo de coisa que ela é, é uma questão de quais tipos de coisas faz sentido dizer com relação ao xadrez, de quais tipos de coisas são, em um sentido lógico, relevantes ou apropriadas de se dizer com relação ao xadrez.22

Além disso, Schwyzer argumenta:

Pertence à gramática do xadrez que possamos dizer coisas tais como "vamos jogar xadrez", "este foi um movimento sagaz (ou tolo)", podemos perguntar quem venceu ou está vencendo, dizer "má sorte" a um e "boa partida" ao outro depois que jogo acaba; estas formas de falar são intrinsecamente relevantes no contexto do xadrez, não no contexto de, digamos, uma Missa. ${ }^{23}$

Da mesma maneira, o fato de que o xadrez pressupõe habilidade pertence à gramática do xadrez.

Similarmente, é devido à sua gramática que o rito do xadrez é diferente do jogo de xadrez. O rito de xadrez, de fato, ao contrário do jogo de xadrez, não é uma forma de competição, assim, não faz sentido falar, no rito do xadrez, sobre vitória e derrota ou mesmo sobre estratégia.

Para Schwyzer, a palavra "gramática" na frase "gramática do xadrez" tem um significado bastante similar ao termo "gramática" usado nos livros escolares comuns de gramática. Similarmente, a gramática como uma teoria da sintaxe denota que "crianças" é um substantivo e "jogar" é um verbo e que é significativo escrever 'As crianças jogam', mas não "o Jogo crianças"; a gramática de uma prática significa que o xadrez é uma competição, e isso denota que faz sentido dizer certas coisas em relação ao xadrez, mas não com relação a outras práticas.

A observação de Schwyzer sugere que há um nível da ação institucional (o nível da atividade que tem um sentido de uma prática, como um sentido de jogo ou um sentido de rito) em que as regras constitutivas não atuam.

Com relação à distinção entre o conceito de atividade constituída pelas regras e o conceito de prática, é claro que agir em concordância com as regras do xadrez não é suficiente para jogar xadrez, da mesma forma que agir de acordo com as regras do futebol não é suficiente para jogar futebol. 


\section{ATIVIDADE CONSTITUIIDA POR REGRAS VS. PRÁTICA}

De maneira a provar que atividades institucionais e instituições não são meramente atividades constituídas por regras, Schwyzer inventou uma nova atividade regida por regras que não é uma prática: $x$-ndo. Escreve Schwyzer:

Suponhamos que eu diga que criei uma nova forma de comportamento, inventei uma nova prática, e estas são as regras. Não, não é um jogo ou uma competição de qualquer tipo, nem um rito ou uma cerimônia, nem é, em nenhum sentido, uma "forma de fazer alguma coisa", como fazer um testamento é uma maneira de fornecer a propriedade de alguém após a morte, com o propósito ínsito. É uma prática completamente nova, chamada "X-ndo"; ela requer dois participantes, o "iniciador" (initiator) e o "respondente" (respondent) e o procedimento é como se segue. Primeiro, o iniciador assina seu nome em um pedaço especial de papel chamado "a almofada"; a assinatura de seu nome é chamada "lançamento". O respondente, então, tem uma escolha: ou ele submete-se, o que significa fazer isto, ou ele... e assim por diante. Todo o negócio é terminado quando o respondente "declara" - ou seja, assina seu nome no outro lado da almofada. ${ }^{24}$

X-ndo é uma atividade regida por regras, isto é, uma atividade cuja natureza consiste em agir em conformidade com suas regras constitutivas. Schwyzer indaga: "O que é X-ndo? Uma atividade de acordo com estas regras."25

Mas esta atividade não tem outros sentidos que este. Não é um jogo ou um rito. Não é uma maneira de fazer alguma coisa como um testamento é uma "maneira de" distribuir a propriedade de alguém depois de sua morte. Para Schwyzer, X-ndo é a uma mera atividade regida por regras que não é uma prática.

Para Schwyzer, X-ndo não é uma prática por três razões diferentes:

(i) Primeiro, "x-ndo não tem uma gramática." ${ }^{26}$ Não existem proposições gramaticais sobre a natureza de X-ndo. Recuperando a filosofia de Ludwig Wittgenstein, Schwyzer ${ }^{27}$ define a gramática de uma atividade como aquela "que a torna uma atividade deste tipo". A gramática é o lugar de sentido (por exemplo, o sentido de rito ou o sentido de jogo) que condiciona a possibilidade de ser uma prática.

(ii) Segundo, não há nenhuma situação que conte como uma situação apropriada para engajar-se em X-ndo. ${ }^{28}$

(iii) Terceiro, $\mathrm{X}$-ndo não tem nenhum outro sentido que o sentido de agir de acordo com suas regras: "Agir de acordo com essas regras não é fazer ou estar comprometido com nenhuma outra que apenas esta, a ação em conformidade com aquelas regras." 29

Ao contrário de X-ndo, o xadrez é, em vez disso, um exemplo de uma atividade regida por regras que é também uma prática. $\mathrm{O} X a d r e z$ é um exemplo de uma atividade que pode ser executada apenas pela ação em conformidade 
com regras constitutivas, porém cujo sentido não se esgota em um simples comportamento que obedece a regras constitutivas. O xadrez é um jogo, mas o fato de ele ser um jogo não é dedutível pelas regras constitutivas do jogo. As regras do xadrez não permitem a compreensão do sentido dessa atividade. $\mathrm{O}$ sentido dessa atividade transcende aquelas regras que constituem a possibilidade do jogo.

Agora, retorno à questão posta inicialmente neste ensaio: a atividade de jogar xadrez consiste em agir de acordo com as regras constitutivas do xadrez?

Minha resposta é negativa. Acredito que jogar xadrez não consiste apenas em agir em conformidade com as regras dele. É óbvio que é um jogo executado pela ação em conformidade com as regras do jogo. É impossível jogar xadrez sem as regras do xadrez. Porém, não é menos verdade que realizar movimentos de acordo com essas regras não é necessariamente jogar xadrez. Uma pessoa que move mecanicamente as peças desse jogo sem uma estratégia ou sem o objeto de xeque-mate não está jogando xadrez. É mesmo possível executar, seguindo as regras do xadrez, uma atividade totalmente diferente deste e também gramaticalmente incompatível com o jogo de xadrez, assim como o rito do xadrez descrito por Schwyzer.

\section{A INVESTIGAC̣ÃO IMPOSSÍVEL DE AVERRÓIS}

Uma tese epistêmica corresponde à minha tese ontológica sobre a natureza da atividade institucional: se não se conhece a gramática de uma prática, não se pode compreender o que a prática é, mesmo que se conheça muito bem as regras constitutivas dessa prática.

Por exemplo, se não se compreende o que um jogo é, se não se conhece a gramática do "jogo", não se pode compreender o que o jogo do xadrez é, mesmo que se conheçam muito bem as regras do xadrez.

Curiosamente, um tipo similar de impossibilidade é descrito em um conto de Jorge Luis Borges: A busca de Averróis. Nesse conto, Borges fala-nos de uma investigação impossível, a investigação de Averróis. Averróis tentou traduzir a Poética de Aristóteles, mas estava fechado nos limites da cultura islâmica e, não conhecendo teatro, não pôde compreender o significado dos termos "tragédia" e "comédia".

\section{REFERÊNCIAS}

BORGES, Jorge Luis. Obras completas. Buenos Aires: Emecé, 1981.

CONTE, Amedeo G. Eidos. An Essay on Constitutive Rules. Poznan Studies in the Philosophy of the Sciences and the Humanities, Netherlands, v. 11, p. 251-257, 1988.

LÉVI-STRAUSS, Claude. La pensée sauvage. Paris: Plon, 1962. 
LORINI, Giuseppe. Dimensioni giuridiche dell'istituzionale. Padua: CEDAM, 2000.

. Oggetto e atto. Torino: Giappichelli, 2008.

MILLER, Dolores. Constitutive Rules and Essential Rules. Philosophical Studies, Netherlands, v. 39, p. 183-197, 1983.

ROVERSI, Corrado. Pragmatica delle regole costitutive. Bologna: GEDIT, 2007.

SCHÄCHTER, Josef. Prolegomena zu einer kritischen Grammatik. Wien: Julius Springer, 1935.

SCHWYZER, Hubert. Rules and Practices. The Philosophical Review, United States, v. 78, p. 451-467, 1969.

SEARLE, John Rogers. Speech Acts. An Essay in the Philosophy of Language. Cambridge: Cambridge University Press, 1969.

. The Construction of Social Reality. New York: Free Press, $1995 .$.

. Making the social world: the structure of human civilization. Oxford: Oxford University Press, 2010.

SWIFT, Jonathan. A Tale of a Tub. In: SWIFT, Jonathan. A Tale of a Tub with Other Early Works (1696-1707). Ed. Louis A. Landa. Oxford: Blackwell, 1960. p. 241-353.

WITTGENSTEIN, Ludwig. Philosophical Investigations. Oxford: Blackwell, 1953.

1969.

. Philosophische Grammatik. Ed. Rush Rhees. Oxford: Basil Blackwell,

ZLANIEC, Wojciech. Fathers, Kings and Promises. Husserl and Reinach on the A Priori. Husserl Studies, Netherlands, v. 9, p. 147-177, 1992.

ZNAMIEROWSKI, Czeslaw. Podstawowe pojêcia teorji prawa I. Poznañ: Fiszer i Majewski, 1924.

1 SEARLE, John Rogers. Speech Acts. An Essay in the Philosophy of Language. Cambridge: Cambridge University Press, 1969. p. 51.

2 SWIFT, Jonathan. A Tale of a Tub. In: SWIFT, Jonathan. A Tale of a Tub with Other Early Works (1696-1707). Ed. Louis A. Landa. Oxford: Blackwell, 1960. p. 283.

3 SEARLE, John Rogers. Speech Acts. An Essay in the Philosophy of Language. Cambridge: Cambridge University Press, 1969. p. 51.

4 Ibid., p. 34.

5 A ideia de que há regras que criam novas possibilidades de ação já pode ser encontrada no trabalho do filósofo do direito polonês Czeslaw Znamierowski (1924). (Cf Giuseppe Lorini, 2000, 69-81)

6 SEARLE, John Rogers. Speech Acts. An Essay in the Philosophy of Language. Cambridge: Cambridge University Press, 1969. p. 33-34.

7 Para esse tipo de regra, Amedeo G. Conte propôs o nome "regra eidético-constitutiva". Conte $(1988,252)$ escreveu: "As regras eidético-constitutivas são aquelas que determinam a conotação daqueles termos que 
(na formulação das regras) designam a praxemes (as unidades da práxis) que são regidas pelas regras. Por exemplo, as regras de xadrez são eidético-constituvias por que (e no sentido em que) elas determinam a conotação dos termos (bispo, torre, check, ...) que designam a praxemes (peças, pragmemes, situações de jogo) do jogo."

8 SCHWYZER, Hubert. Rules and Practices. The Philosophical Review, United States, v. 78, p. 454, 1969.

9 Ibid., p. 464.

10 SCHÄCHTER, Josef. Prolegomena zu einer kritischen Grammatik. Wien: Julius Springer, 1935.

11 SCHWYZER, Hubert. Rules and Practices. The Philosophical Review, United States, v. 78, p. 463, 1969.

12 Ibid., p. 456.

13 Ibid., p. 456.

14 Ibid., p. 457.

15 SCHWYZER, Hubert. Rules and Practices. The Philosophical Review, United States, v. 78, p. 457, 1969. Vitória em um jogo é um fenômeno muito interessante para a investigação da realidade institucional. Vitória em um jogo como o xadrez pressupõe a existência da instituição do xadrez. Não se pode vencer uma partida de xadrez se a instituição jogo de xadrez não existir. Porém, o sentido de vitória e o sentido de derrota, na esfera de uma instituição, parece ir além dos limites da instituição individualmente. As instituições determinam as condições de vitória e derrota e, assim, a extensão das palavras 'vitória' e 'derrota' na esfera de uma instituição como xadrez ou futebol. Porém, a intenção das duas palavras não é determinada pelas instituições que determinam as condições de vitória e derrota. Ludwig Wittgenstein (1969) indaga: "Em que consiste ganhar ou perder em um jogo?" E ele responde: "Claro que não é na situação de jogo que se produz a vitória". O sentido de 'vitória' e o sentido de 'derrota' parecem ir além dos limites de uma instituição singular. A Vitória e a derrota parecem não ser conceitos institucionais, porém parecem mais conceitos metainstitucionais (devo a frase "conceito institucional" a Dolores Miller $(1981,191))$ : eles não têm nas instituições suas próprias condições de possibilidade, mas, ao contrário, eles constituem as condições de possibilidade de certas instituições como jogos competitivos. Além disso, um sinal de sua metainstitucionalidade é constituído por sua transinstitucionalidade. De fato, enquanto as condições de vitória e de derrota mudam quando mudamos de um jogo para outro, o significado de 'vitória' e o significado de 'derrota' permanecem imodificados.

16 Um caso similar é descrito por Claude Lévi-Strauss (1983, p.46). Ele descreve o caso de Gahuku-Gama, povo de Nova Guiné «qui ont appris le football, mais qui jouent, plusieurs jours de suite, autant de parties qu'il est nécessaire pour que s'équilibrent exactement celles perdues et celles gagnées par chaque camp» (que aprenderam o futebol mas que jogam, durante vários dias seguidos, o número necessário de partidas para que se equilibrem vitórias e derrotas de ambos os lados). Eles consideram «un jeu comme un rite» (um jogo como um rito).

17 SCHWYZER, Hubert. Rules and Practices. The Philosophical Review, United States, v. 78, p. 464, 1969.

18 Idem.

19 Ibid., p. 463.

20 Idem.

21 Aqui, há quatro exemplos de proposições gramaticais do ensaio de Schwyzer: (i) As promessas devem ser mantidas, (ii) $\mathrm{O}$ xadrez é um jogo competitivo, (iii) As sensações são particulares, (iv) A expectativa é um estado.

22 Schwyzer pede emprestado o termo 'gramática' de Ludwig Wittgenstein (1953), que escreveu nos $\S \S$ 371 e 373: "A essência é expressa pela gramática. [...] A Gramática diz que tipo de objeto algo é". SCHWYZER, Hubert. Rules and Practices. The Philosophical Review, United States, v. 78, p. 454, 1969.

23 Ibid., p. 455.

24 Ibid., p. 464.

25 Idem.

26 Ibid., p. 465.

27 Ibid., p. 454.

28 Ibid., p. 465.

29 Ibid., p. 466. 


\title{
CAN CONSTITUTIVE RULES CREATE A PRACTICE?
}

\begin{abstract}
The author investigates the role of constitutive rules in the construction of social reality. He denies that constitutive rules are a sufficient condition of a practice such as a chess game. To create a new practice with rules, it is necessary that there already be the grammar of this practice, that is, the sense of this practice (for example, the sense of game). It is the grammar of a practice and not its constitutive rules that determines the nature of a practice. The sense of a practice cannot be created by constitutive rules.
\end{abstract}

Keywords: Constitutive rules. Practice. Social ontology. Institutional fact.

Submetido: 7 abr. 2016 Aprovado: 23 maio 2016 